\title{
Three new species of Hagnagora Druce, 1885 (Lepidoptera, Geometridae, Larentiinae) from Ecuador and Costa Rica and a concise revision of the genus
}

\author{
Gunnar Brehm' \\ I Institut für Spezielle Zoologie und Evolutionsbiologie mit Phyletischem Museum, Vor dem Neutor 1, 07743 \\ Jena, Germany \\ Corresponding author: Gunnar Brehm (gunnar.brehm@uni-jena.de) \\ Academic editor: A. Hausmann | Received 22 June 2015 | Accepted 22 October 2015 | Published 18 November 2015 \\ http://zoobank.org/EA901A84-CB13-4889-A77C-07E89EDA172E \\ Citation: Brehm G (2015) Three new species of Hagnagora Druce, 1885 (Lepidoptera, Geometridae, Larentiinae) from \\ Ecuador and Costa Rica and a concise revision of the genus. ZooKeys 537: 131-156. doi: 10.3897/zookeys.537.6090
}

\begin{abstract}
Three new Hagnagora Druce species (Geometridae, Larentiinae) are described: Hagnagora richardi Brehm, sp. n. from Ecuador, H. hedwigae Brehm, sp. n. from Ecuador, and H. mirandahenrichae Brehm, sp. n. from Costa Rica. A checklist of taxa assigned to Hagnagora is provided. Hagnagora is provisionally divided into six clades: the anicata clade (6 species), the buckleyi clade (3 species), the croceitincta clade (3 species), the ephestris clade (3 species), the mortipax clade ( 4 species) and $H$. subrosea (1 species). Two taxa are revived from synonymy: $H$. catagrammina Druce, stat. rev. and $H$. luteoradiata Thierry-Mieg, stat. rev. Two taxa are reinstated from subspecies to species level: $H$. acothysta Schaus, stat. rev. and $H$. jamaicensis Schaus, stat. rev. Four taxa are provisionally removed from Hagnagora: "Hagnagora" ignipennis, "Hagnagora" mesenata, "Hagnagora" vittata, and "Hagnagora" ceraria. After these changes, the genus Hagnagora now comprises 20 valid species.
\end{abstract}

\section{Keywords}

Taxonomy, Hagnagora, Costa Rica, Ecuador

Copyright Gunnar Brehm. This is an open access article distributed under the terms of the Creative Commons Attribution License (CC BY 4.0), which permits unrestricted use, distribution, and reproduction in any medium, provided the original author and source are credited. 


\section{Introduction}

The Neotropical genus Hagnagora was invented by Druce (1885a) and described by Druce (1885b). So far, it comprised 23 described taxa, with 16 valid species (Parsons et al. 1999, Brehm and Sullivan 2005, Sullivan 2011). One species, $H$. mortipax Butler, was subdivided into three subspecies. Eighty-three percent of all taxa had been described by 1913, followed by one taxon described in 1927 and three over the last decade. This pattern appears typical for Neotropical geometrid genera (Brehm et al. 2011). The assignment of taxa to Hagnagora is largely based on the Lepidoptera card index of the Natural History Museum in London (NHM), and subsequently from the catalogue of geometrid moths (Parsons et al. 1999). During identification work on Ecuadorian and Costa Rican geometrid moths, it became obvious that Hagnagora - like most Neotropical geometrid genera - requires revision. In this paper, I attempt to solve some of the most urgent taxonomic problems of the genus. I describe three new species, revive two species from synonymy, transfer two species from subspecies to species level, and provisionally exclude four taxa from the genus. With one exception, all known taxa assigned to Hagnagora are illustrated. I also include available molecular genetic data (COI gene) in order to aid species identification. This consice revision will be a basis of future taxonomic work that will be required, e.g. with regard to the question whether Hagnagora is monophyletic or consists of two separate lineages.

\section{Species identities and Barcode of Life Data Systems}

Species delimitation and description of Lepidoptera has traditionally focused on their external morphology, mostly wing patterns. These formed the basis of all original descriptions of taxa assigned to Hagnagora in past centuries. The latest three species descriptions additionally contain not only colour plates, but also illustrations of male and female genitalia (Brehm and Sullivan 2005, Sullivan 2011). Additionally, molecular genetic information is available for these three taxa in the form of sequence data for the 658 bp fragment of the mitochondrial Cytochrome Oxidase I gene ("COI-barcodes"). A system of unique Barcode Index Numbers (BINs) has been established by Barcode of Life Data Systems (www.boldsystems.org) (Ratnasingham and Hebert 2013). It usually allows a quick and reliable assignment of specimens to other specimens in the system, whether identified to species or higher taxonomic level. Barcoding of all type specimens is an ultimate goal that would greatly increase the reliability of identifications, particularly in poorly studied tropical regions, and in cryptic and 'difficult' arthropod taxa. However, while barcoding of old type specimens is possible and relatively cheap (Strutzenberger et al. 2012), financial and bureaucratic constraints are still impeding a large-scale molecular analysis of type specimens in museums. In this paper, assignment of barcodes to described species was therefore performed by careful comparison of type 
material with freshly collected material, and all respective specimens are illustrated. The assignments are working hypotheses until original types are eventually barcoded. Twelve different BINs are assigned to different Hagnagora species in this paper, thus covering a substantial part of the known taxa. In one case, one BIN has been assigned to two taxa that nonetheless are treated as morphologically separate species.

To accelarate the taxonomic progress and following a recently reached consensus amongst geometrid taxonomists (Forum Herbulot 2014), this study focuses not on extensive species descriptions, but on diagnostic characters and the synthesis of illustrated external characters, genitalia structures and COI barcodes.

\section{Methods}

Moths were pinned and dissected following established techniques (Lafontaine 2004, Hünefeld et al. 2011). Genitalia slides were embedded in Euparal, stained with Chlorazol Black, and digitised using an Olympus dotSlide system with 10x magnification. Adult moths were photographed in raw format using a $60 \mathrm{~mm}$ Nikkor macro lens mounted on a Nikon D700 camera. Photos were adjusted and colour plates were mounted using Photoshop and InDesign software (Adobe Systems, San José, USA).

Sequencing of the barcode fragment of the COI gene was carried out at the Canadian Center for DNA barcoding in Guelph, Ontario. Barcode sequences were compared by nearest neighbour analyses (Kimura 2 parameter), as implemented on the Barcode of Life Data Systems website (Ratnasingham and Hebert 2007). The resulting trees represent preliminary hypotheses of taxa groupings and can form the basis of future phylogenetic work. Fig. 1 shows a summary tree of all available taxa with barcode data. It visualizes similarities and differences in the COI gene between the different taxa and it was instrumental in differentiating four of the six provisional larger clades indentified within Hagnagora.

The following acronyms are used for institutions in which the specimens are deposited:

CISEC Colección de Invertebrados del Sur del Ecuador, Universidad Tecnica Particular Loja, Ecuador

NHM Natural History Museum, London, UK

PMJ Phyletisches Museum, Jena, Germany

RCGB Research Collection Gunnar Brehm, Jena, Germany

SMF Senckenberg Museum, Frankfurt a. M., Germany

SMNS Staatliches Museum für Naturkunde, Stuttgart, Germany

USNM National Museum of Natural History [formerly United States National Museum], Washington D.C., USA

ZSM Zoologische Staatssammlung, München, Germany 


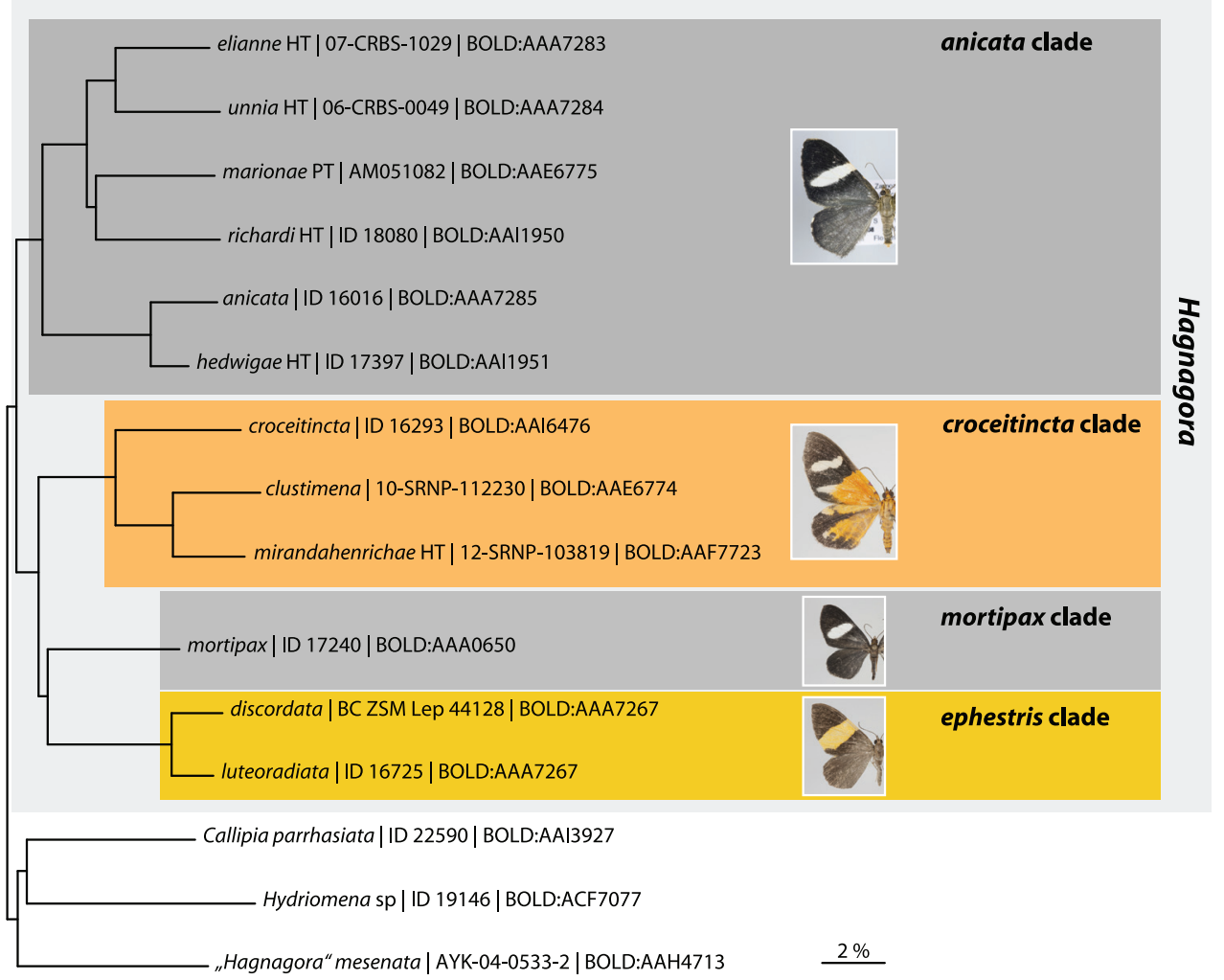

Figure I. Summary tree of the available molecular genetic data based on genetic COI 'barcodes' using the Kimura 2 parameter implemented in BOLD systems. Four out of six clades are represented by the barcode data; no data were available for the buckleyi clade and for H. subrosea. "Hagnagora" mesenata groups outside Hagnagora sensu stricto. The species name is followed by the individual identification number and the Barcode Index Number (BIN). HT: Holotype, PT: Paratype.

\section{Results and Discussion}

\section{Distribution and Biology}

Species previously assigned to Hagnagora were described from a wide range of Central and South American countries ranging from Mexico and Jamaica $\left(17-18^{\circ} \mathrm{N}\right)$ to Chile (Valdivia province, ca. $39^{\circ} \mathrm{S}$ ). Table 1 provides an overview of all taxa. The southernmost type locality of any Hagnagora species considered in this paper is Valparaíso in Chile $\left(33^{\circ} \mathrm{S}\right)$ for $H$. discordata, but this record needs confirmation. Judging from their type localities, most species have a predominantly montane distribution. This includes the three recently described Costa Rican species (Brehm and Sullivan 2005, Sullivan 2011), as well as species described from the Colombian, Ecuadorian, Peruvian and Chilean Andes and mountains in SE Brazil. 


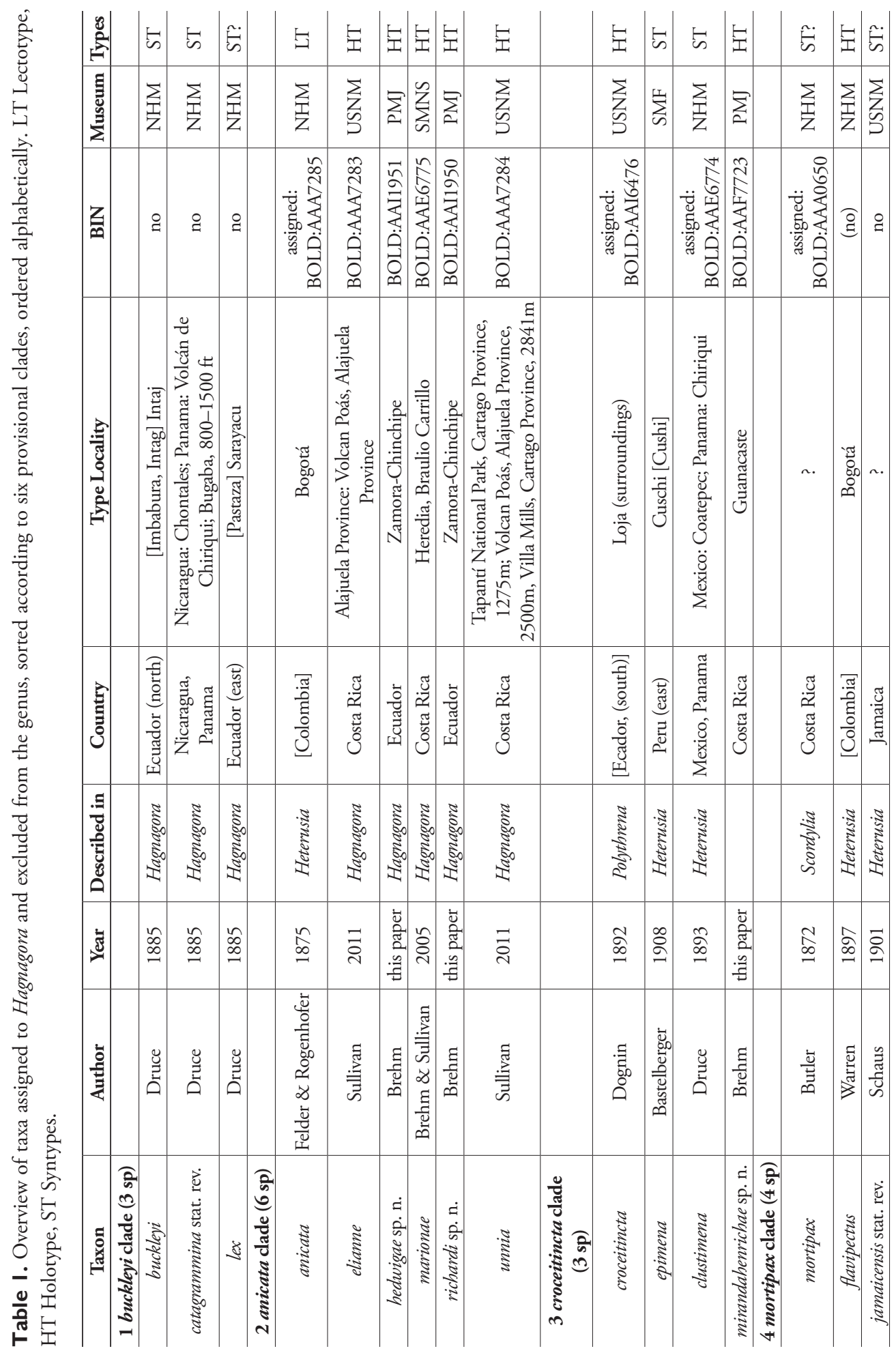




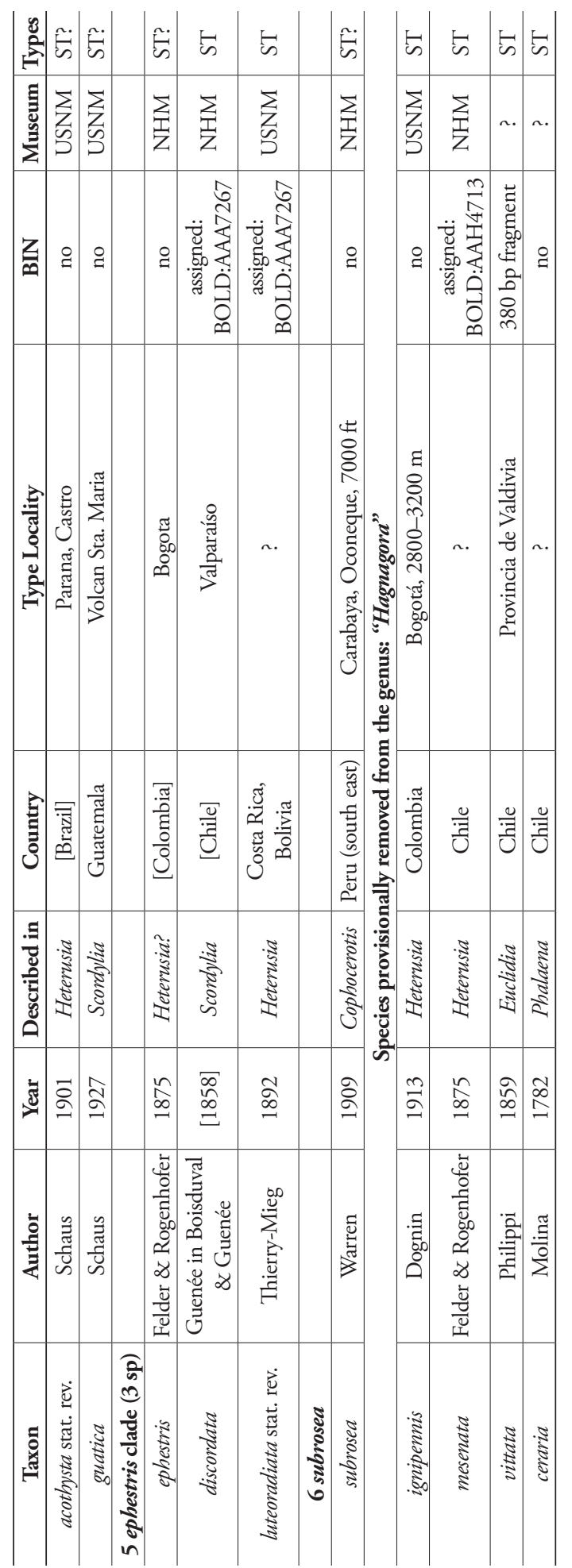


Caterpillars of Hagnagora are only known for $H$. mortipax and $H$. luteoradiata from NW Costa Rica (Janzen and Hallwachs 2014; http://janzen.bio.upenn.edu/caterpillars/database.lasso). Both species' caterpilars were recorded on Clethra mexicana DC. (Ericales, Clethraceae) (Figs 42, 43). One species excluded in this paper from Hagnagora, i.e. "Hagnagora" vittata, was reared in captivity on Fuchsia magellanica LAM. (Onagraceae) (King and Parra 2011). King and Parra (2011) also described the morphology of the egg and larva of "Hagnagora" vittata.

Hagnagora imagines mandatorily fold their wings vertically while resting in the same way as most butterflies (Fig. 41). They share this behaviour with genera such as Callipia Guenée and Erateina Doubleday (personal observations), whereas most geometrids display different resting positions. Hagnagora species are frequently observed at night and are readily attracted to artificial light sources (Brehm 2002, Brehm and Sullivan 2005), while both diurnal and nocturnal activity has been recorded for $H$. marionae and "Hagnagora" vittata (Brehm and Sullivan 2005, King and Parra 2011). Furthermore, both mud puddling and diurnal activity of Hagnagora mortipax has been observed in Peru (www.flickr.com/photos/76033499@N00/15919107346/). Apart from these isolated observations, little is known about the behaviour and ecology of Hagnagora moths.

\section{Hagnagora: a monophyletic genus?}

Druce (1885a) described Hagnagora buckleyi and H. lex, and shortly defined the genus together with the description of $H$. catagrammina (Druce 1885b). Druce (1885b) established Hagnagora largely by comparison with Anemplocia splendens (Druce, 1885) due to differences in the wing shape. The colourful $H$. buckleyi clade shares an apparently unique combination of wing pattern characters (Figs 2-6): The forewings have an orange transversal band, and the hindwings display fields of metallic blue between the veins. Notably, Druce (1893) did not include $H$. clustimena Druce, $H$. discordata Gn, and H. mortipax Butler in Hagnagora, but assigned them to Heterusia Hübner. Recent molecular genetic studies have shown that Heterusia sp. and Hagnagora mortipax are closely related, but do not form a monophyletic group (Sihvonen et al. 2011). Parsons et al. (1999), following the card index of the Natural History Museum, transferred several species previously assigned to Heterusia to Hagnagora.

All species assigned to Hagnagora in this revision share distinct wing patterns including a conspicuous white or yellow transversal band or blotch on the forewing. In addition, members of the clades anicata, ephestris and mortipax share a striated pattern on the hindwing underside. The croceitincta clade and $H$. subrosea show remnants of this striation, but the members of the buckleyi clade display distinctly different hindwing patterns. Molecular genetic data are available for all groups, but unfortunately with the exception of the buckleyi clade and H. subrosea. In a genetic dataset including more than 1,400 species of Ecuadorian geometrid species, the six recorded Hagnagora species representing four different clades form a single cluster (Brehm et al. 2013). This 
strongly suggests that at least these four clades form a monophyletic group (see also Fig. 1). Further molecular genetic data and genitalia dissections are required for members of the buckleyi clade to test whether the entire group represents a monophyletic taxon or possibly consists of two distinct lineages.

\section{Taxonomy of Hagnagora}

An overview of all taxa is provided in Table 1, and an overview of new type specimens and reference specimens with Bardode Index Numbers (BINs) and GenBank Accessions is provided in Table 2 .

\section{1 buckleyi clade}

\section{Hagnagora buckleyi Druce, 1885}

no assigned BIN

Figs 2, 3

Type locality. Ecuador, Intaj [possibly Intag, Imbabura province].

Remarks. Druce (1885a) described H. buckleyi and H. lex. The upper- and undersides of the wings in $H$. buckleyi are very similar, with the colour of the hindwings generally being paler. The forewings feature a deep orange transversal band on a dark brown background, and the hindwings show metallic blue fields between the veins, with three located on the upperside between $\mathrm{M}_{3}$ and $\mathrm{CuA}_{2}$ and one in the cell, and eight between all veins on the underside. The pattern of the female is similar, with the blue fields extending further on the forewing, including the blotch between veins $\mathrm{CuA}_{2}$ and $\mathrm{A}$. In the female, metallic blue scales are also present at the base of the forewing at both the wing upper- and underside.

Distribution. North-western Ecuador.

Diagnosis. The largest species of the clade. The extension of the blue fields is significantly larger than in $H$. lex. The orange transversal band on the forewing is more saturated and more rounded than in $H$. catagrammina. Form and extension of the metallic blue blotches are different from those in $H$. catagrammina (Figs 2-3, 5-6).

\section{Hagnagora catagrammina Druce, 1885, stat. rev.}

no assigned BIN

Figs 5, 6

Type locality. Nicaragua: Chontales; Panama: Volcán de Chiriqui; Bugaba, 800-1500ft.

Remarks. Druce (1885b) described catagrammina in the same year, but separately from $H$. buckleyi and $H$. lex. The taxon was put in synonymy with buckleyi by Parsons et 


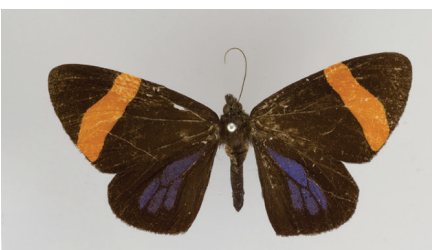

2a-b buckleyi male, lectotype

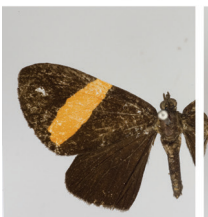

4a-b lex lectotype
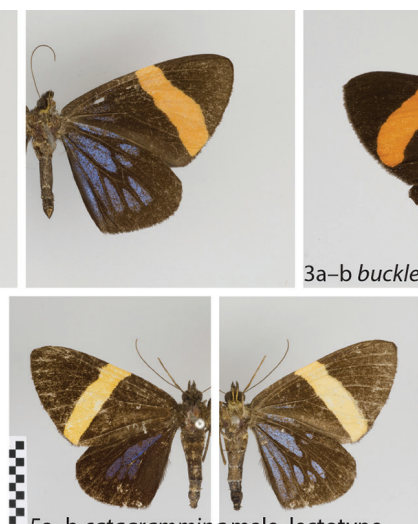

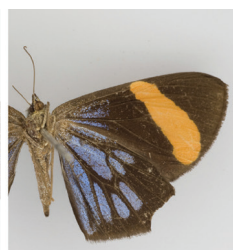

kleyi female, paralectotype

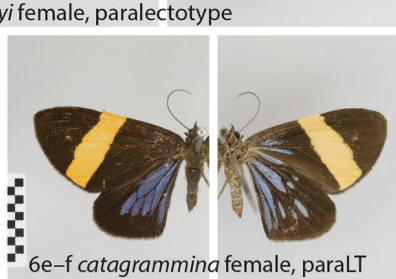

Figures 2-6. 2 Hagnagora buckleyi Druce male, lectotype a dorsal view b ventral view $\mathbf{3} H$. buckleyi female, paralectotype a dorsal view $\mathbf{b}$ ventral view $\mathbf{4} H$. lex Druce male, lectotype a dorsal view $\mathbf{b}$ ventral view 5 H. catagrammina Druce male, lectotype a dorsal view b ventral view $\mathbf{6}$ H. catagrammina Druce female, paralectotype (paraLT) a dorsal view $\mathbf{b}$ ventral view.

Table 2. Voucher specimens (types and reference specimens for Barcode Index Numbers (BINs) with identification numbers, GenBank Accession numbers and BINs.

\begin{tabular}{c|c|c|c|c}
\hline Species & Voucher number & GenBank Accession & Type & BIN \\
\hline marionae & GB 014 & AM051082.1 & paratype & BOLD:AAE6775 \\
\hline anicata & ID 16016 & HQ576490 & BIN reference & BOLD:AAA7285 \\
\hline elianne & 07-CRBS-1029 & no & holotype & BOLD:AAA7283 \\
\hline unnia & 06-CRBS-0049 & no & holotype & BOLD:AAA7284 \\
\hline richardi & ID 18080 & KT208284 & holotype & BOLD:AAI1950 \\
\hline richardi & ID 15855 & KT208285 & paratype & BOLD:AAI1950 \\
\hline richardi & ID 16285 & JF859087 & paratype & BOLD:AAI1950 \\
\hline richardi & BC ZSM Lep 04774 & no & paratype & BOLD:AAI1950 \\
\hline richardi & ID 17328 & GU671808 & paratype & BOLD:AAI1950 \\
\hline richardi & ID 16119 & JF858934 & paratype & BOLD:AAI1950 \\
\hline richardi & ID 17863 & HM380148 & paratype & BOLD:AAI1950 \\
\hline hedwigae & ID 17397 & HM432223 & holotype & BOLD:AAI1951 \\
\hline croceitincta & ID 16293 & JF859094 & BIN reference & BOLD:AAI6476 \\
\hline clustimena & 10-SRNP-112230 & JF846078 & BIN reference & BOLD:AAE6774 \\
\hline mirandahenrichae & $12-S R N P-103819$ & no & holotype & BOLD:AAF7723 \\
\hline mirandahenrichae & 07-SRNP-103401 & JQ566645 & paratype & BOLD:AAF7723 \\
\hline mirandahenrichae & 07-SRNP-103498 & JQ566696 & paratype & BOLD:AAF7723 \\
\hline mirandahenrichae & 11-SRNP-102035 & JQ545536 & paratype & BOLD:AAF7723 \\
\hline mirandahenrichae & $11-S R N P-102036$ & JQ545537 & paratype & BOLD:AAF7723 \\
\hline mirandahenrichae & $12-S R N P-105462$ & no & paratype & BOLD:AAF7723 \\
\hline mortipax & ID 17240 & GU671855 & BIN reference & BOLD:AAA0650 \\
\hline discordata & BC ZSM Lep 44128 & no & BIN reference & BOLD:AAA7267 \\
\hline luteoradiata & ID 16725 & HQ576573 & BIN reference & BOLD:AAA7267 \\
\hline mesenata & AYK-04-0533-2 & KF491827 & BIN reference & BOLD:AAH4713 \\
\hline vittata & BC LP 0092 & no & BIN reference & no BIN \\
\hline & & & \\
\hline
\end{tabular}


al. (1999). As noted by Druce, catagrammina is closely related to the other two species of the clade and particularly similar to $H$. buckleyi. In agreement with Druces' original description of the three taxa, I revive the species from synonymy with $H$. buckleyi due to small but overall significant differences of the wing patterns. The morphological differences hint to different species, particularly given the experience from many other species complexes of Neotropical Geometridae in which often more subtle differences - ideally combined with results from genitalia morphology and barcoding - can be observed in different species.

Distribution. Central America, from Nicaragua to Panama.

Diagnosis. The extension of the blue blotches is significantly larger than in $H$. lex. The transversal band on the forewing is paler and straighter than in H. catagrammina. Form and extension of the metallic blue blotches are different from those in $H$. buckleyi (Figs 2-3).

\section{Hagnagora lex Druce, 1885}

no assigned BIN

Fig. 4

Type locality. Ecuador (east), [Pastaza], Sarayacu.

Remarks. Hagnagora lex was described by Druce (1885a) together with H. buckleyi. While buckleyi was collected on the western slopes of the Andes, $H$. lex originates from the Amazon slopes of the Eastern Andes.

Distribution. Eastern Ecuadorian Andes (Pastaza: Sarayacu).

Diagnosis. Smaller than $H$. buckleyi and of similar size to $H$. catagrammina. The extension of the blue blotches is significantly smaller than in $H$. buckleyi. The form of the transversal band on the forewing is similar to that in H. buckleyi, but the band does not stretch as far towards the wing margins. H. lex is the species with the smallest extensions of metallic blue blotches on the underside, with the upperside completely devoit of these blotches.

\section{2 anicata clade}

Hagnagora anicata (Felder \& Rogenhofer, 1875)

BIN: BOLD:AAA7285

Figs 7, 8

Type locality. [Colombia], Bogotá.

Remarks. $H$. anicata was re-described with a description also of the male genitalia, by Sullivan (2013). The lectotype is illustrated in Fig. 7. A series of specimens collected in southern Ecuador (1999-2013) (Fig. 8) is indistinguishable from $H$. anicata and therefore regarded as conspecific. The female (Fig. 12) is larger than the 


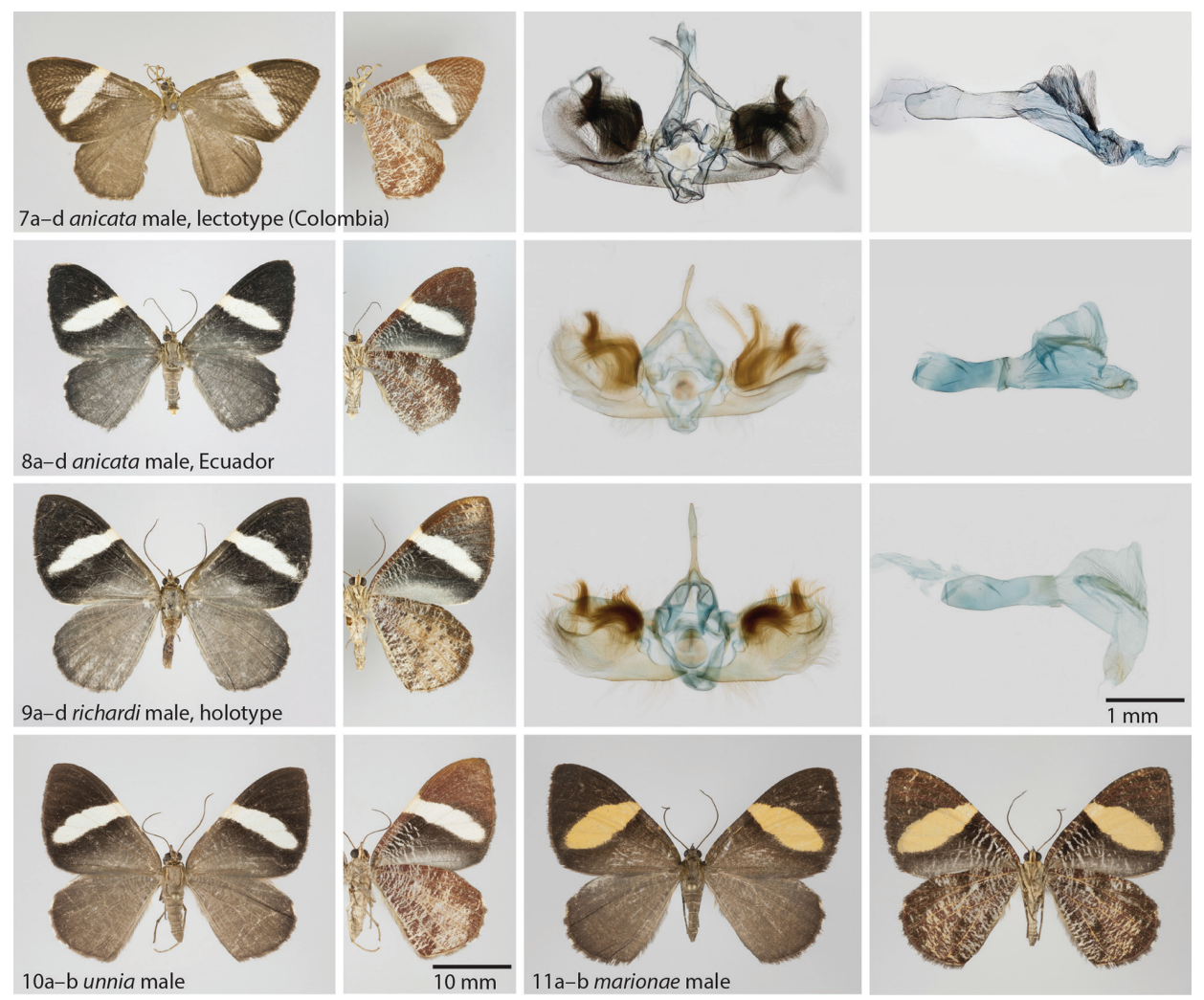

Figures 7-I I. 7 Hagnagora anicata (F\&R), male lectotype a dorsal view b ventral view $\mathbf{c}$ valvae d aedeagus 8 H. anicata (F\&R), male from Ecuador as reference specimen with Barcode Index Number (BIN) $\mathbf{a}$ dorsal view $\mathbf{b}$ ventral view $\mathbf{c}$ valvae $\mathbf{d}$ aedeagus $\mathbf{9} H$. richardi $\mathrm{sp}$. n., male holotype $\mathbf{a}$ dorsal view $\mathbf{b}$ ventral view $\mathbf{c}$ valvae $\mathbf{d}$ aedeagus $\mathbf{I} \mathbf{H}$. unnia Sullivan, male a dorsal view b ventral view II $H$. marionae Brehm $\&$ Sullivan, male a dorsal view $\mathbf{b}$ ventral view.

male. A living specimen is shown in Fig. 41 in the typical resting position of these beautiful moths.

Distribution. Apart from its Colombian type locality, H. anicata has recently been collected and barcoded from sites in southern Ecuador to central Bolivia at elevations ranging from 2000 to $2920 \mathrm{~m}$ a.s.l.

Diagnosis. Most species of the $H$. anicata clade are very similar, and the most reliable current method for diagnosis is the COI barcode. H. anicata tends to be smaller than the other species occurring sympatrically, namely $H$. richardi and $H$. hedwigae: The wing length of the male (holotype) is only $17.5 \mathrm{~mm}$ in comparison to $19 \mathrm{~mm}$ in the male holotype of $H$. richardi. The structures of the female signum are also more complex than in $H$. richardi, but similar to those in $H$. hedwigae. The uncus of the male is smaller and shorter than in $H$. richardi. Aedeagi of the known males are $(H$. anicata and $H$. richardi) similar. COI barcode: The minimum observed distance to the presumbably most closely related species $(H$. hedwigae) is $3.1 \%$. 
Hagnagora elianne Sullivan, 2011

Not figured (very similar to $H$. unnia)

BIN (paratype): BOLD:AAA7283

Voucher 07-CRBS-1029

Type locality (holotype). Costa Rica: Alajuela Province, Poás Volcano National Park, $2500 \mathrm{~m}$.

Remarks. H. elianne was described and illustrated by Sullivan (2011). The species closely resembles the other species in the $H$. anicata clade, particularly $H$. unnia.

Distribution. The species has recently been collected and barcoded in Honduras (Cortes Province) and in several provinces of Costa Rica at elevations ranging from 1480 to $2840 \mathrm{~m}$ a.s.l.

Diagnosis. Males are on average slightly larger than males in $H$. unnia and can be distinguished from $H$. anicata by a swollen as opposed to a gently tapered distal half of the uncus and by the absence of a moderately large, upcurved spine at the end of the costa in $H$. elianne (Sullivan 2011). Females may be distinguished from females of $H$. unnia by their longer, more complex signum. COI barcode: The minimum observed distance to the presumably most closely related species $(H$. unnia) is $5.0 \%$.

\section{Hagnagora unnia Sullivan, 2011}

BIN (paratype): BOLD:AAA7284

Voucher 06-CRBS-0049

Fig. 10

Type locality (holotype): Costa Rica, Cartago Province, Tapantí National Park, 1275 m.

Remarks. H. unnia was recently described and illustrated by Sullivan (2011).

Distribution. The species is known from several provinces in Costa Rica at elevations ranging from 587 to $2840 \mathrm{~m}$ a.s.l.

Diagnosis. The species closely resembles other species of the $H$. anicata clade, particularly $H$. elianne; see there for a diagnosis. COI barcode: The minimum observed distance to the presumably most closely related species (H. elianne) is $5.0 \%$.

\section{Hagnagora marionae Brehm \& Sullivan, 2005}

BIN (paratype): BOLD:AAE6775

GenBank Accession: AM051082

Fig. 11

Type locality. Costa Rica, Heredia province, Braulio Carrillo National Park, Volcán Barva, $2730 \mathrm{~m}$ a.s.l.

Remarks. H. marionae was described and illustrated by Brehm and Sullivan (2005). 
Distribution. The species has been collected only at two high mountain areas in Costa Rica at elevations $>2500 \mathrm{~m}$ a.s.l.

Diagnosis. The species resembles the other species of the $H$. anicata clade, but is easily distinguished by large orange-yellow blotches on the forewing. Males have a spatula-shaped uncus. COI barcode: The minimum observed distance to the presumably most closely related species $(H$. richardi) is $6.6 \%$.

Hagnagora richardi Brehm, sp. n.

http://zoobank.org/406E12C4-4231-49F2-BE51-61E504E395F7

BIN (holotype): BOLD:AAI1950

Voucher ID 18080

GenBank Accession: KT208284

Figs 9,13

Type material. Holotype: male (Fig. 9): Ecuador, Loja province, Parque Nacional Podocarpus, Cajanuma, 0406.85'S, 79¹0.47'W, 2916 m, 20 November 2008, G. Brehm leg. (ID 18080, genitalia preparation, barcode sequence 658 bp) (PMJ).
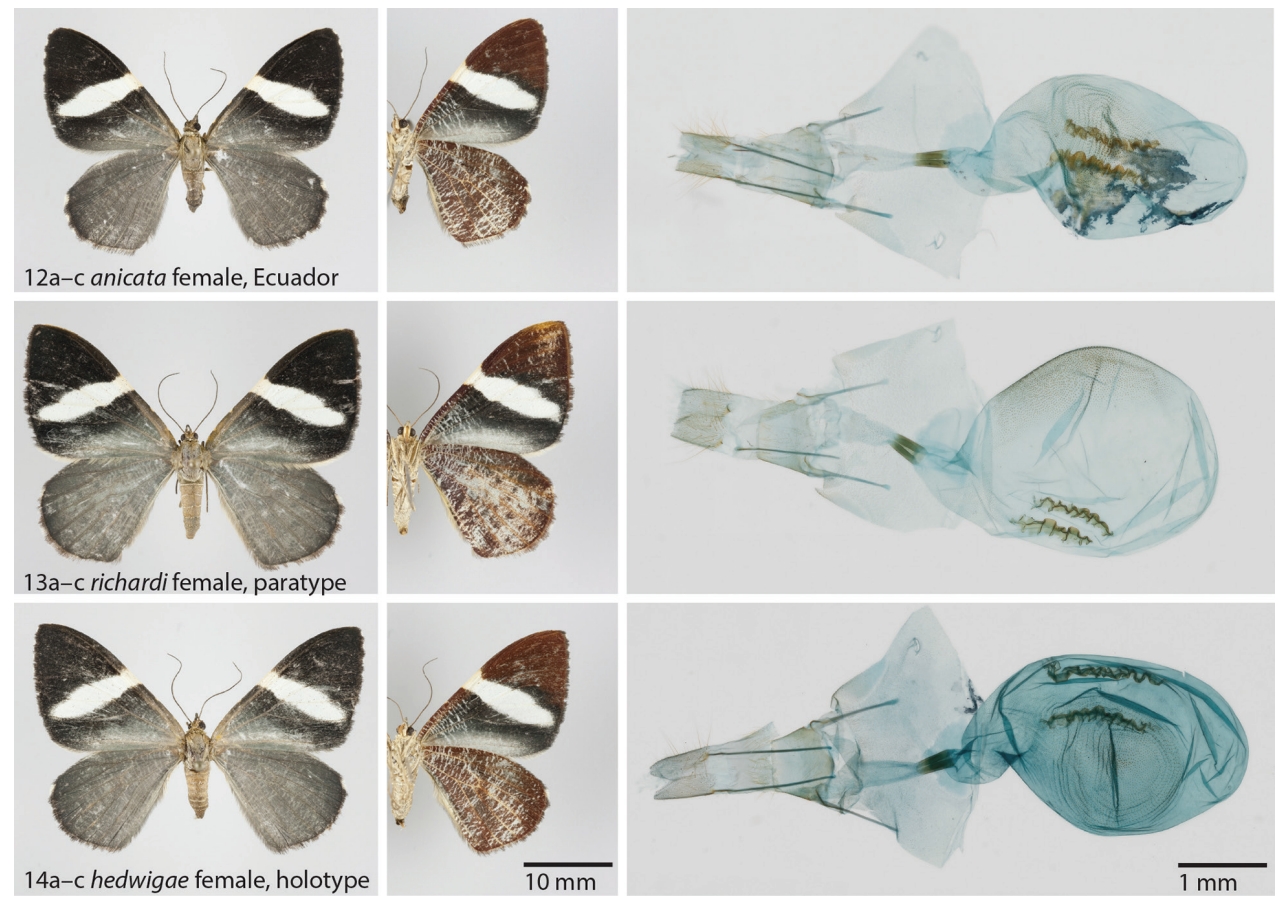

Figures 12-14. I 2 H. anicata (F\&R), female from Ecuador as reference specimen with Barcode Index Number (BIN) a dorsal view $\mathbf{b}$ ventral view $\mathbf{c}$ genitalia $\mathbf{I} \mathbf{3}$. richardi sp. n., female, paratype a dorsal view b ventral view $\mathbf{C}$ genitalia $\mathbf{1} \mathbf{H}$. hedwigae sp. n., female, paratype a dorsal view b ventral view $\mathbf{c}$ genitalia. 
Paratypes: (deposited in CISEC, PMJ, RCGB, ZSM) 4 males, 2 females. 1 female: same as holotype but $04^{\circ} 06.866^{\prime} \mathrm{S}, 79^{\circ} 10.46^{\prime} \mathrm{W}, 2897 \mathrm{~m}, \mathrm{~F}$. Bodner leg. (ID 15855, barcode sequence 658 bp); 1 female (Fig. 13): Ecuador, Zamora Chinchipe, Reserva Biológica San Francisco, 03⒌72'S, 7904.44'W, $2180 \mathrm{~m}$, 16 November 2008, F. Bodner leg. (ID 16285, barcode sequence 658 bp); 1 male same as previous but 28 October 1999, D. Süßenbach leg. (BC ZSM Lep 04774, barcode sequence $529 \mathrm{bp}$ ); 1 male: same as previous but $03^{\circ} 59.65^{\prime} \mathrm{S}, 79^{\circ} 04.10^{\prime} \mathrm{W}$, $2670 \mathrm{~m}, \mathrm{G}$. Brehm leg. (ID 17328, barcode sequence $658 \mathrm{bp}$ ); 1 male as previous but $03^{\circ} 59.68^{\prime} \mathrm{S}, 79^{\circ} 04.10^{\prime} \mathrm{W}, 2677 \mathrm{~m}, 18$ November 2008 (ID 16119, barcode sequence $658 \mathrm{bp}$ ); 1 male as previous but 25 November 2008 (ID 17863, barcode sequence $621 \mathrm{bp}$ ).

Description. As illustrated in Figs 9, 13. The wing length of the holotype (male) is $19 \mathrm{~mm}$. The wing length of a female paratype (Fig. 13) is $21 \mathrm{~mm}$.

Distribution. Only known from a small region around Podocarpus National Park, provinces Zamora-Chinchipe and Loja, Ecuador, with an observed elevational range of 2180-3021 m a.s.l. Apart from the Type locality and nearby sites, specimens were collected at elevations at ca. $3000 \mathrm{~m}$ at Cerro Toledo in the same National Park $\left(04^{\circ} 23^{\prime} \mathrm{S}, 79^{\circ} 07^{\prime} \mathrm{W}\right)$. However, this record is not fully reliable because genitalia preparation or barcoding was not conducted for these specimens.

Diagnosis. Closely resembles other species of the $H$. anicata clade. On average significantly larger than $H$. anicata, but the female has about the same size as $H$. hedwigae. The uncus of the male is larger and broader than in $H$. anicata. The signum of the bursa copulatrix is less complex than in $H$. anicata and $H$. hedwigae. Easily distinguishable from $H$. marionae by the cream-white colour of the blotches on the forewing. COI barcode: The minimum observed distance to the presumably most closely related species (H. marionae) is $6.6 \%$.

Etymology. Hagnagora richardi is named in honour of Richard Philipp from Jena, Germany, in recognition of his and his parents' support for the taxonomy of Neotropical geometrid moths.

\section{Hagnagora hedwigae Brehm, sp. $\mathrm{n}$.}

http://zoobank.org/91A46B5D-DF10-42A8-97B2-46E0D5D7E086

BIN (holotype): BOLD:AAI1951

Voucher ID 17397

GenBank Accession HM432223

Fig. 14

Type material. Holotype: female (Fig. 14): Ecuador, Loja province, Reserva Biológica San Francisco, 0359.68'S, 7904.10'W, 2677 m, 25 November 2008, G. Brehm leg. (ID 17397, genitalia preparation, barcode sequence 595 bp) (PMJ).

Description. As illustrated in Fig. 14. 
Distribution. Only a single female is known from $H$. hedwigae collected in southern Ecuador $(2677 \mathrm{~m}$ ). The wing length of the holotype (female) is $21 \mathrm{~mm}$ (same size as richardi).

Diagnosis. Resembles most closely $H$. anicata and $H$. richardi, but is larger than $H$. anicata, and the signum of the bursa copulatrix is more complex than in $H$. richardi. COI barcode: The minimum observed distance to the presumably most closely related species (H. anicata) is $3.1 \%$.

Etymology. Hagnagora hedwigae is named in memory of Hedwig Seppelt (*1919 in Baumgarten, Silesia; † 2013 in Korschenbroich, Germany). Mrs Seppelt loved nature, and she took care that birds, small animals and insects found a habitat in her garden. The name is given in recognition of support for the taxonomy of Neotropical geometrid moths provided by her daughter-in-law Irmgard and her son Winfried Seppelt.

\section{3 croceitincta clade}

\section{Hagnagora croceitincta (Dognin, 1892)}

BIN: BOLD:AAI6476

Figs $15-17$

epimena (Bastelberger, 1908): Type locality. Peru (east), Cuschi [Cushi]

Type locality. [Ecador, (south)], Loja surroundings.

Remarks. H. croceitincta was described by Dognin from southern Ecuador where it has recently been collected in montane forests (Brehm 2002). As one of the largest known Hagnagora species, it is conspicuously coloured, with orange, dark brown and white patterns. The taxon epimena (Bastelberger) remains in synonymy because the lectotype specimen (Fig. 16) does not show any particular differences to the type specimen of $H$. croceitincta (Fig. 15).

Distribution. Recently collected and barcoded specimens were sampled from central Colombia to southeastern Peru at elevations between 1750 and $2540 \mathrm{~m}$ a.s.l.

Diagnosis. On average larger than the closely related species $H$. clustimena and $H$. mirandahenrichae: Forewing length of the female holotype reaches $23 \mathrm{~mm}$ in comparison to about $20 \mathrm{~mm}$ in the other species. On the forewing, the white transversal blotch does not stretch to the costal margin as seen in the other two species, and the apical, dark-brown area reaches beyond veins $1 \mathrm{~A}+2 \mathrm{~A}$. The species is also generally more vividly coloured than the other species in this clade, with white spots on the forewing between veins $\mathrm{CuA}_{2}$ and $1 \mathrm{~A}+2 \mathrm{~A}$ and around $\mathrm{M}_{3}$ on the upperside of the hindwing. COI barcode: The minimum observed distance to the presumably most closely related species (H. mirandahenrichae) is $7.1 \%$. 


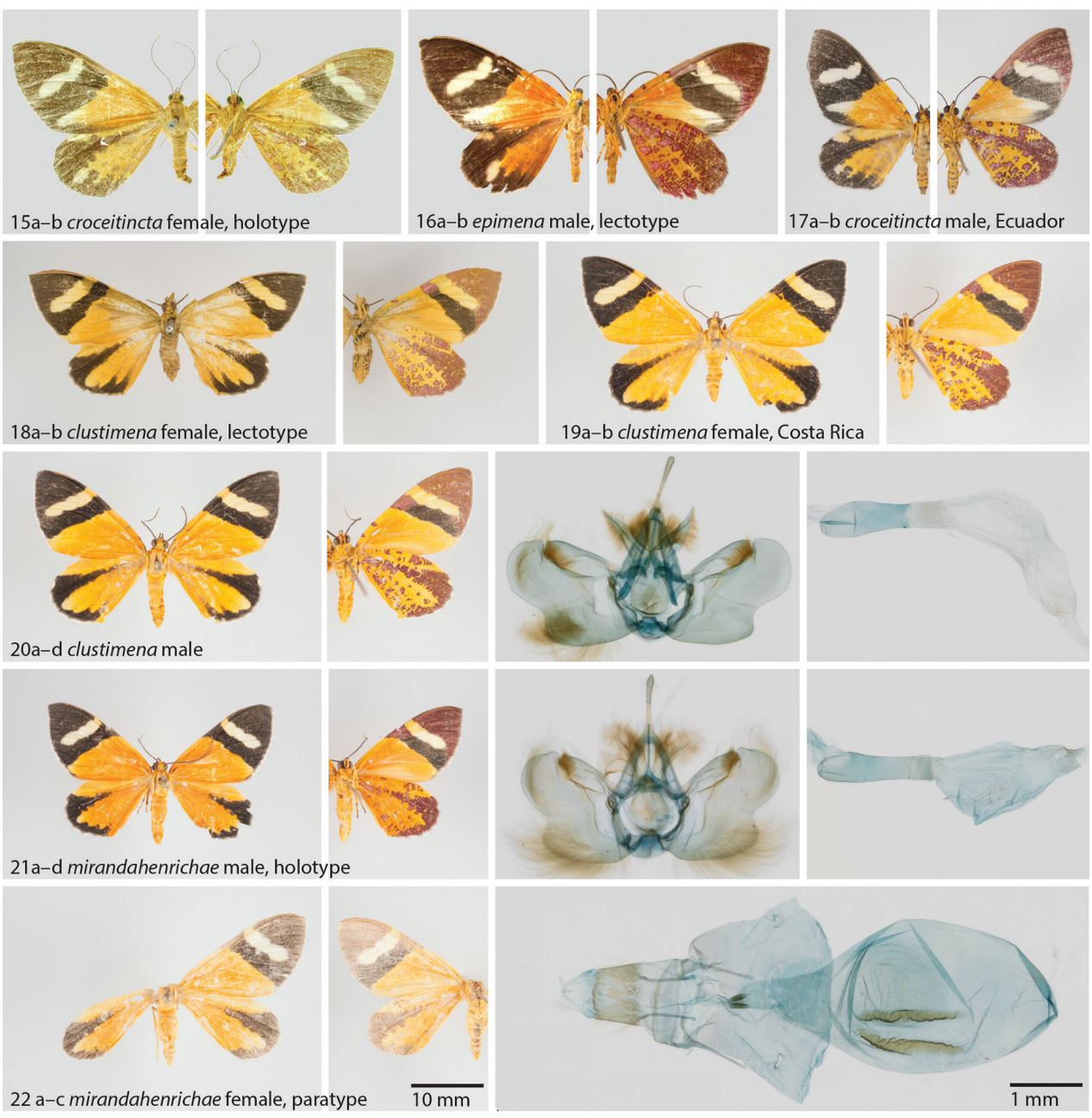

Figures 15-22. I5 Hagnagora croceitincta (Dognin) female, holotype a dorsal view b ventral view $16 \mathrm{H}$. epimena (Bastelberger) male, lectotype a dorsal view $\mathbf{b}$ ventral view $\mathbf{1 7} \mathrm{H}$. croceitincta male from Ecuador as reference specimen with Barcode Index Number (BIN) a dorsal view b ventral view $18 \mathrm{H}$. clustimena (Druce) female, lectotype $\mathbf{a}$ dorsal view $\mathbf{b}$ ventral view $\mathbf{1 9} \mathrm{H}$. clustimena female from Costa Rica as reference specimen with Barcode Index Number (BIN) 20 H. clustimena male from Costa Rica as reference specimen with Barcode Index Number (BIN) a dorsal view b ventral view $\mathbf{c}$ valvae $\mathbf{d}$ aedeagus 2I $H$. mirandahenrichae Brehm sp. n. male, holotype a dorsal view $\mathbf{b}$ ventral view $\mathbf{c}$ valvae $\mathbf{d}$ aedeagus $22 \mathrm{H}$. mirandahenrichae female, paratype a dorsal view b ventral view $\mathbf{c}$ genitalia.

\section{Hagnagora clustimena (Druce, 1893)}

BIN: BOLD:AAE6774

Figs $18-20$

Type locality. Mexico: Coatepec. 
Remarks. H. clustimena was originally assigned by Druce to Heterusia and then transferred to Hagnagora by Parsons et al. (1999). H. clustimena and H. croceitincta appear to occur allopatrically.

Distribution. Besides the type specimens described by Druce from Mexico and Panama, recently collected and barcoded specimens were sampled in Honduras and Costa Rica between 850 and $1550 \mathrm{~m}$ a.s.l.

Diagnosis. On average smaller than $H$. croceitincta and slightly larger than $H$. mirandahenrichae (see $H$. croceitincta). The white transversal blotch on the forewing stretches to the costal margin and the apical dark-brown area reaches vein $\mathrm{CuA}_{2}$, as also observed in mirandahenrichae. H. clustimena is slightly paler than $H$. mirandahenrichae. The male genitalia of both species are similar, but the valves are broader and differently shaped to mirandahenrichae. COI barcode: The minimum observed distance to the presumably most closely related species (H. mirandahenrichae) is $4.6 \%$.

\section{Hagnagora mirandahenrichae Brehm, sp. $\mathrm{n}$.}

http://zoobank.org/4C4FF729-5872-412A-BEF4-2428DA894237

BIN (holotype) BOLD:AAF7723

Figs 21-22

Type locality. Costa Rica, Área de Conservación Guanacaste, Guanacaste province.

Type material. Holotype: male (Fig. 21): Costa Rica, Guanacaste province, Área de Conservación Guanacaste, Sector Santa Maria, Mirador Santa Maria, $10.766^{\circ} \mathrm{N}$, $85.301^{\circ} \mathrm{W}, 920 \mathrm{~m}$ a.s.l., 20 June 2012, S. Rios \& R. Franco leg. (voucher 12-SRNP103819, genitalia preparation, barcode sequence 658 bp) (PMJ).

Paratypes: (deposited in PMJ, USNM) 5 males, 1 female. Costa Rica, Guanacaste province, Área de Conservación Guanacaste, Sector Pitilla, Estacion Pitilla, 10.989 N, $85.426^{\circ}$ W, 675 m a.s.l.; 1 female (Fig. 22) 16 May 2007, F. Quesada \& R. Franco leg. (voucher 07-SRNP-103401, genitalia preparation, barcode sequence $658 \mathrm{bp}$ ), 1 male same as previous but 17 May 2007 (voucher 07-SRNP-103498), 2 males, 02 Apr 2011, H. Cambronero \& S. Rios leg. (vouchers 11-SRNP-102035 and 11-SRNP102036, barcode sequences 658 bp), 1 male 12 November 2012, R. Franco \& H. Cambronero leg. (voucher 12-SRNP-105462).

Description. As illustrated in Figs 21, 22.

Distribution. Only known from sectors Santa Maria and Pitilla from Área de Conservación Guanacaste, province Guanacaste, NW Costa Rica, at elevations ranging from 675-920 $\mathrm{m}$ a.s.l., and therefore with a lower elevational range than $H$. clustimena (observed: $850-1550 \mathrm{~m}$ a.s.l.).

Diagnosis. Easily distinguished from $H$. croceitincta by its wing patterns (see diagnosis in that species). The yellow ground colour of $H$. mirandahenrichae is slightly more intensive than in $H$. clustimena. The male genitalia of both species are similar, but the valves of mirandahenrichae are narrower and have a different shape to clustimena. COI barcode: The minimum observed distance to the presumably closest relative, $H$. clustimena, is $4.6 \%$. 
Etymology. Hagnagora mirandahenrichae is named in honour of Ms. Miranda Henrich of California in recognition of her and her mother's critical support for understanding the taxonomy and biodiversity development of the Área de Conservación Guanacaste (ACG) in northwestern Costa Rica, where this species has been found by the ACG caterpillar inventory (Janzen et al. 2014).

\section{4 mortipax clade}

Hagnagora mortipax (Butler, 1872)

BIN: BOLD:AAA0650

Figs 23-25

flavipectus (Warren, 1897): Type locality. [Colombia], Bogotá.

\section{Type locality. Costa Rica.}

Remarks. H. mortipax is one of the earliest described species in the genus and among the smallest Hagnagora species. Together with $H$. luteoradiata it also has the largest known geographical range. The taxon flavipectus remains in synonymy because it falls within the confirmed geographical range of mortipax and shows no significant deviations from the type specimen of mortipax. In comparison to the type specimen, the extension of the large white blotch on the forewing is smaller in Ecuadorian specimens, where it does not reach the costal margin. Since the barcode sequences of Costa Rican and Ecuadorian populations are nearly identical, all respective specimens are treated as members of the same species, and slight differences in wing patterns are regarded as geographical variability.

Distribution. Recently sampled and barcoded material is either from Costa Rica (Fig. 24) or Ecuador (Fig. 25), from elevations ranging from 540-2180 m a.s.l., and additional material from Ecuador falls within the same elevational range (Brehm 2002).

Diagnosis. The upper side of the wing in H. mortipax has a dark brown base colour with a large cream-white blotch on the forewing. This blotch almost reaches the outer margin, also either reaching the costal margin (Costa Rican specimens), or scantily not (Ecuadorian specimens). The white blotch is narrower in $H$. jamaicensis (Fig. 27), and significantly smaller, and separated from the outer margin, in $H$. acothysta from Brazil. All three species are significantly larger than $H$. guatica.

Hagnagora jamaicensis (Schaus, 1901), stat. rev. no assigned BIN

Fig. 27

Type locality. Jamaica. 


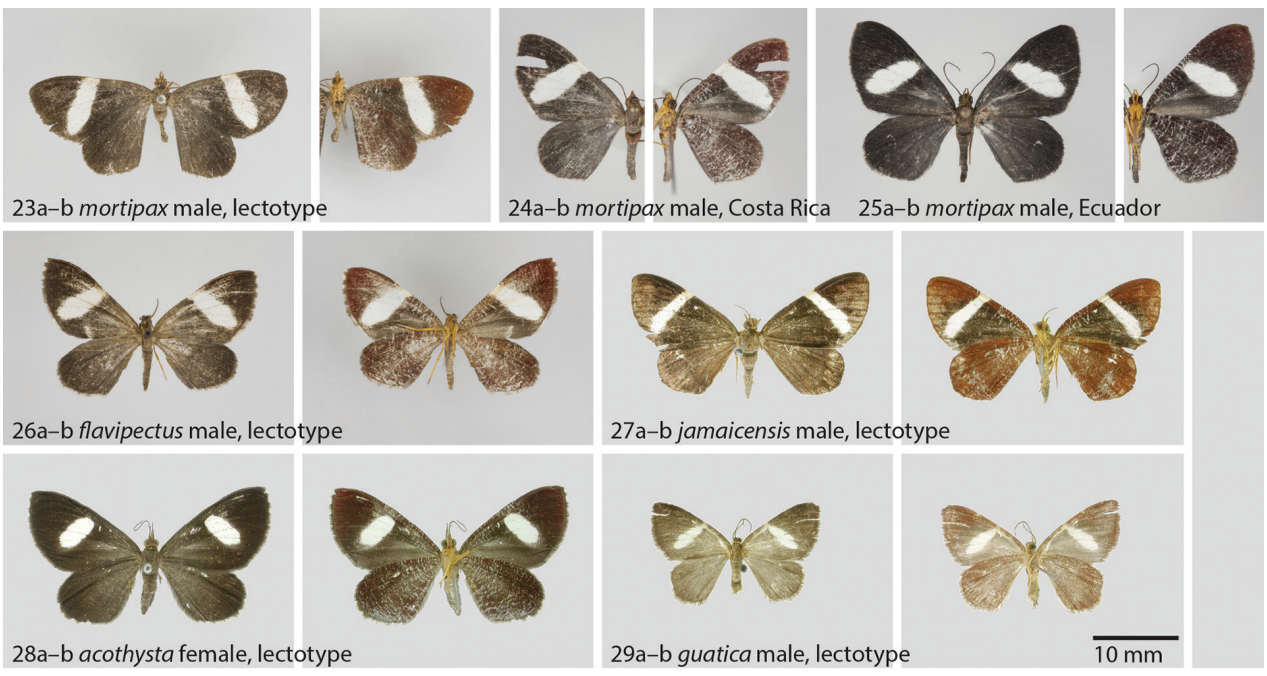

Figures 23-29. 23 Hagnagora moripax (Druce) male, lectotype a dorsal view b ventral view $24 H$. mortipax male from Costa Rica as reference specimen with Barcode Index Number (BIN) a dorsal view b ventral view $25 H$. mortipax male from Ecuador as reference specimen with Barcode Index Number (BIN) a dorsal view b ventral view $\mathbf{2 6}$ H. flavipectus (Warren) male, holotype a dorsal view b ventral view 27 H. mortipax jamaicensis (Schaus) male, lectotype a dorsal view b ventral view (photo USNM) $28 H$. mortipax acothysta (Schaus) female, lectotype a dorsal view b ventral view (photo USNM) 29 H. guatica (Schaus) female, lectotype a dorsal view b ventral view (photo USNM).

Remarks. Originally described as a Heterusia species by Schaus (1901), this taxon was down-ranked as a subspecies of mortipax by Parsons et al. (1999). In my view, the significantly different wing pattern in jamaicensis justifies Schaus' original species rank, but further evidence from barcoding is desirable in order to consolidate its species status.

Distribution. Jamaica.

Diagnosis. In contrast to the other taxa in the mortipax clade, this species displays a very narrow, cream-white transversal band on the forewings. The striation on the underside of the hindwing is reduced in comparison to mortipax and acothysta.

\section{Hagnagora acothysta (Schaus, 1901), stat. rev.} no assigned BIN

Fig. 28

Type locality. [Brazil], Parana, Castro.

Remarks. Together with jamaicensis, Schaus (1901) originally placed this species in the genus Heterusia. It was then ranked down as a subspecies of mortipax by Parsons et 
al. (1999). The major characteristic of acothysta is the reduction of the white transversal band (found both in mortipax and jamaicensis) to a smaller blotch that reaches about half the area found in mortipax. As in jamaicensis, further evidence from barcoding is desirable for the consolidation of the species status.

Distribution. Brazil.

Diagnosis. Unlike mortipax and jamaicensis, this species shows no white transversal band on the forewing, but rather a reduced blotch that reaches only about $50 \%$ of the size observed in mortipax.

\section{Hagnagora guatica (Schaus, 1927)}

no assigned BIN

Fig. 29

Type locality. Guatemala, [Quetzaltenango Department], Volcán Sta. Maria.

Remarks. Schaus described guatica as belonging to Scordylia Gn (a junior synonym of Heterusia). The wing pattern of guatica strongly resembles that of other members in the mortipax clade, but the species lacks the typical striation on the underside of the hindwing. Further evidence from barcoding and the study of the genitalia will help to better understand the relationships of this species with other species of the mortipax clade.

Distribution. Guatemala.

Diagnosis. By far the smallest Hagnagora species. The species lacks the typical striation on the underside of the hindwing found in all other members of the mortipax clade.

\section{5 ephestris clade}

\section{Hagnagora ephestris (Felder \& Rogenhofer, 1875)}

no assigned BIN

Fig. 30

\section{Type locality. [Colombia], Bogota.}

Remarks. Felder \& Rogenhofer described this species from Colombia. It closely resembles $H$. discordata and $H$. luteoradiata. Parsons et al. (1999) put luteoradiata in synonymy with ephestris, but freshly collected material from Costa Rica and Ecuador shows that luteoradiata consistently lacks yellow blotches on the hindwing. It appears therefore to be more likely that ephestris is a junior synonym of discordata, and an increased knowledge of COI sequences could help to solve this question. Given the current state of knowledge, it appears to be the most appropriate solution to revive luteoradiata from synonymy and to treat the other two taxa as full species.

Distribution. Colombia. 

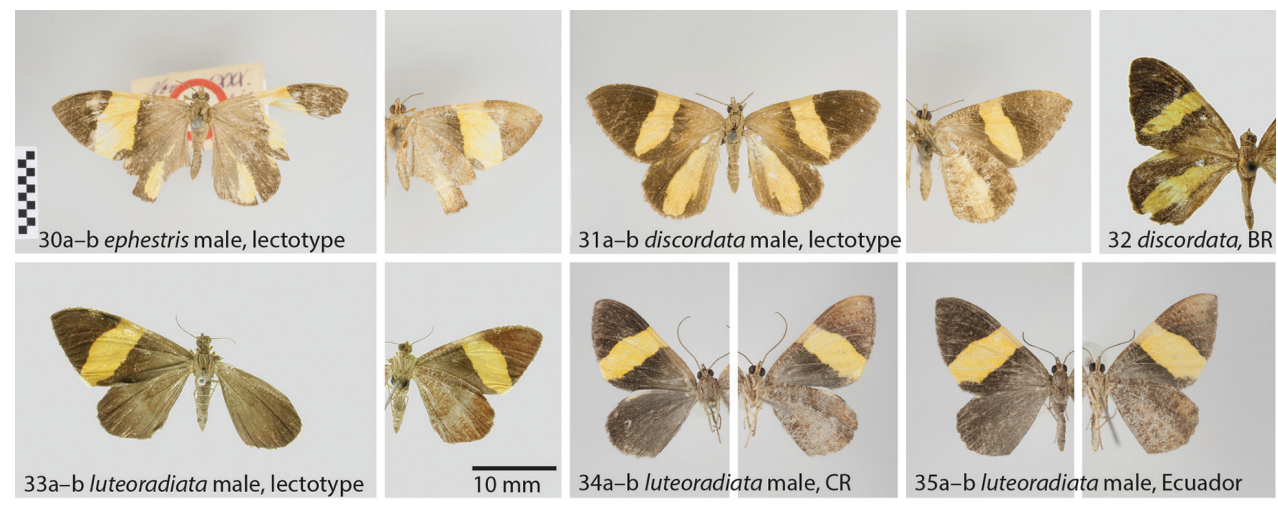

Figures 30-35. 30 Hagnagora ephestris (F\&R) male, lectotype a dorsal view $\mathbf{b}$ ventral view $\mathbf{3} \mathbf{I} H$. discordata male, lectotype a dorsal view b ventral view $32 \mathrm{H}$. discordata male (ZSM Lep 44128) from Brazil as reference specimen with Barcode Index Number (BIN) (photo ZSM) 33 H. luteoradiata (T-M) male, lectotype a dorsal view b ventral view $\mathbf{3 4}$ H. luteoradiata (T-M) male from Costa Rica (CR) as reference specimen with Barcode Index Number (BIN) a dorsal view b ventral view 35 H. luteoradiata (T-M) male from Ecuador as reference specimen with Barcode Index Number (BIN) a dorsal view b ventral view.

Diagnosis. Both ephestris and discordata show a pronounced yellow blotch on the hindwings that is absent in luteoradiata. Different from discordata, the yellow transversal band on the forewing of $H$. ephestris reaches the outer margin of the wing. Moreover, the band is broader than in discordata, whereas the yellow field of the hindwing is narrower, particularly in the proximate half of the wing.

\section{Hagnagora discordata (Guenée [1858])}

BIN: BOLD:AAA7267 (together with luteoradiata)

Figs 31,32

Type locality. [Chile], Valparaíso [possibly incorrect locality].

Remarks. The oldest described Hagnagora species, assigned by Guenée to Scordylia Gn (= Heterusia). The Type locality, given as Valparaíso, [Chile], requires confirmation. The cool-dry climate of this Chilean lowland region differs strongly from the wet montane habitats where other Hagnagora species are typically found.

Distribution. Apart from the doubtful type locality in Chile, recently collected specimens were sampled in Santa Catarina, Brazil $\left(27^{\circ} \mathrm{S}\right)$, at elevations of $1300 \mathrm{~m}$ a.s.l.

Diagnosis. Both discordata and ephestris show a pronounced yellow blotch on the hindwings that is absent in luteoradiata. The yellow transversal band on the forewing is narrower than in ephestris, and it does not reach the outer margin of the wing. The yellow blotch on the hindwing is much broader than in $H$. discordata. COI barcode: The minimum observed distance of Brazilian $H$. discordata is $2.3 \%$ to $H$. luteoradiata from Costa Rica and $2.6 \%$ to $H$. luteoradiata from Ecuador. These short distances suggest a relatively young split within this species clade. 
Hagnagora luteoradiata (Thierry-Mieg, 1892), stat. rev.

BIN: BOLD:AAA7267 (together with discordata)

Figs 33-35

\section{Type locality. Costa Rica.}

Remarks. H. luteoradiata was put in synonymy with $H$. ephestris by Parsons et al. (1999). However, luteoradiata specimens consistently do not show any yellow blotches on the hindwing as observed in ephestris and clustimena. Barcoded specimens from Costa Rica (Fig. 34) and Ecuador (Fig. 35) are genetically very similar (distance only ca. $1.1 \%$ ) and, together with the highly similar appearance, are therefore regarded as conspecific. The ephestris type specimen from Bogotá, Colombia, falls within the geographical range of the luteoradiata specimens, but shows a different wing pattern, i.e. a prominent yellow blotch on the hindwing and a different shape of the blotch of the forewing. The taxon luteoradiata is therefore revived from synonymy.

Distribution. Costa Rica to Ecuador. Observed elevational range in Ecuador $1800-2890 \mathrm{~m}$ and $560-1480 \mathrm{~m}$ in Costa Rica.

Diagnosis. The most prominent difference is the absence of any yellow blotches on the hindwing that are present both in ephestris and discordata. The transversal yellow band on the forewing is broader than in discordata, and has a different shape than in ephestris.

\section{6 subrosea}

\section{Hagnagora subrosea (Warren, 1909)}

no assigned BIN

Fig. 36

Type locality. Peru (south east), Carabaya, Oconeque, $7000 \mathrm{ft}$.
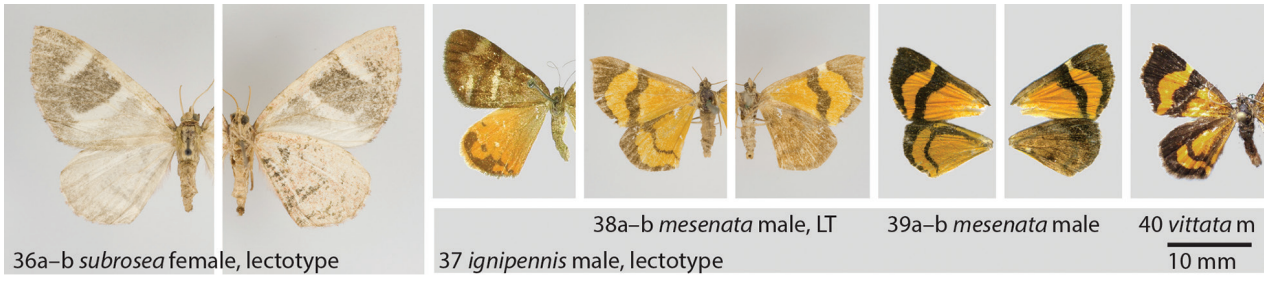

Figures 36-40. 36 Hagnagora subrosea (Warren) female, lectotype a dorsal view b ventral view 37 "Hagnagora" ignipennis (Dognin) male, lectotype dorsal view 38 "Hagnagora" mesenata (F\&R) male, lectotype (LT) a dorsal view b ventral view 39 "Hagnagora” mesenata male (AYK-04-0533-2) from Chile as reference specimen with Barcode Index Number (BIN) a dorsal view b ventral view (photo K Mitter) 40 "Hagnagora" vittata (Philippi) male (m) (BC LP 0092) from Chile as reference specimen with $380 \mathrm{bp}$ COI fragment, dorsal view (photo LE Parra). 
Remarks. Warren originally assigned subrosea to Cophocerotis Warren, but the genus-defining type species, $C$. jaspeata (Dognin), does not show the two prominent white transversal bands of the forewing present in subrosea. Parsons et al. (1999) transferred the species to Hagnagora. Barcoding and genitalia dissections of fresh specimens from this species are required, but judging from the two transversal bands, subrosea might indeed be associated with the croceitincta clade.

Distribution. Peru.

Diagnosis. H. subrosea has a unique combination of a pale brown wing colour with two white transversal bands on the forewings not found in any other species of Hagnagora.

\section{Species excluded from Hagnagora}

The following species are provisionally removed from the genus Hagnagora and set in quotation marks, following the convention applied by Parsons et al. (1999). "Hagnagora" ignipennis (Fig. 37) from Colombia lacks most of the characteristics typical for Hagnagora, notably transversal bands on the forewing. "Hagnagora" mesenata, "Hagnagora" vittata and "Hagnagora" ceraria (Figs 38-40) appear to be closely related to each other, but the wing pattern and particularly the wing shape diverge strongly from other species treated as "true" Hagnagora in this paper. A full barcode sequence is available for "Hagnagora" mesenata, and a $380 \mathrm{bp}$ fragment of the COI gene is available for "Hagnagora" vittata. Both sequences reveal that these species are probably not congeneric with "true" Hagnagora. It is possible that the clades around ignipennis and vittata represent undescribed Larentiinae genera, and both cases require closer examination and a thorough revision of Neotropical Larentiinae.

\section{"Hagnagora" ignipennis (Dognin, 1913)}

no assigned BIN

Fig. 37

Type locality. Colombia, Bogotá, 2800-3200 m.

\section{“Hagnagora" mesenata (Felder \& Rogenhofer, 1875) \\ assigned BIN: BOLD:AAH4713 of voucher specimen AYK-04-0533-2 from Chile GenBank Accession: KF491827}

Figs 38, 39

Type locality. Chile. 

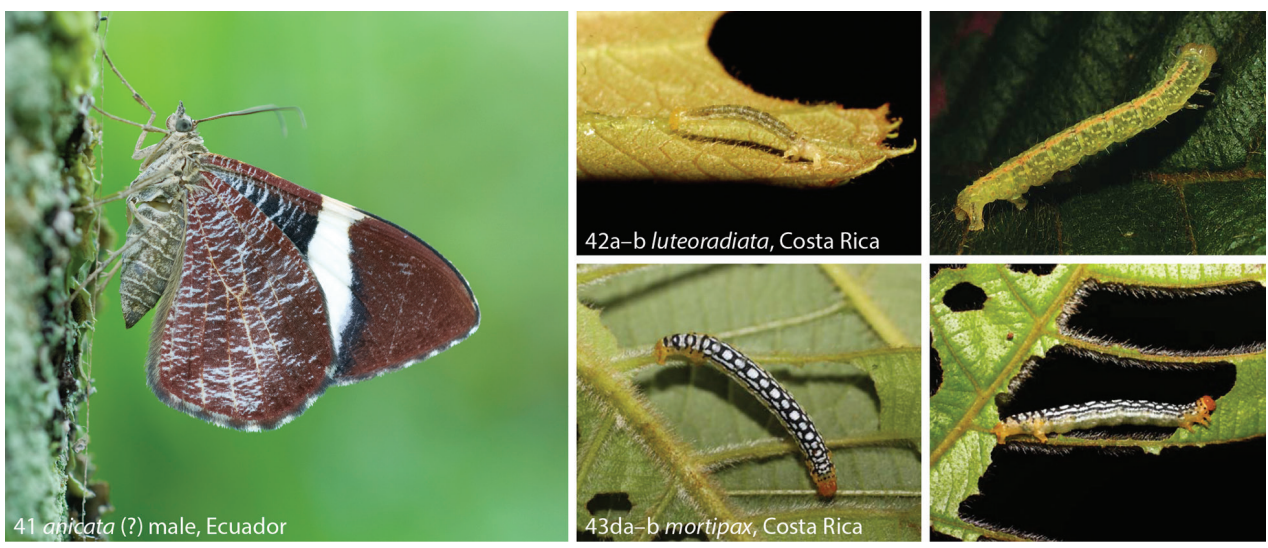

Figures 4I-43. Hagnagora living specimens 4I Hagnagora anicata (?), Ecuador, Zamora Chinchipe, Estación Biológica San Francisco, 22 November 2008 in typical resting habitus, but alert because of disturbance by the photographer. The tympanal organ at the base of the abdomen is well visible $\mathbf{4 2 ~ H a g}$ nagora luteoradiata from Costa Rica a young caterpillar (09-SRNP-31840-DHJ458869) b caterpillar in last instar (09-SRNP-31840-DHJ458860) 43 Hagnagora mortipax caterpillar from Costa Rica a dorsal view (14-SRNP-3240-DHJ487561) b lateral view (14-SRNP-3240-DHJ487557).

\section{“Hagnagora" vittata (Philippi, 1859)}

no BIN assigned but 380 bp COI fragment of voucher specimen BC LP 0092 from Chile Fig. 40

ceraria (Molina, 1782): Type locality. Chile

Type locality. Chile, Provincia de Valdivia.

\section{Acknowledgements}

Jan Axmacher thankfully helped to improve the manuscript linguistically, and Manfred Sommerer and an anonymous reviewer provided valuable comments. Axel Hausmann, Daniel H. Janzen, Winnie Hallwachs, Luis E. Parra, and Bolling Sullivan shared their barcoding data of Hagnagora specimens. Sequence analysis was enabled by funding from Genome Canada through the Ontario Genomics Institute in support of the International Barcode of Life Project and by the Basler Stiftung für biologische Forschung, Basel, Switzerland. DHJ and $\mathrm{WH}$ provided $H$. mirandahenrichae specimens collected in NW Costa Rica, and shared photographs of Hagnagora caterpillars. The Costa Rican specimens and data (DHJ \& WH) were supported by Área de Conservación Guanacaste, INBio, the Wege Foundation, and Permian Global. Niklas Wahlberg kindly gave advice with regard to the phylogenetic interpretation of barcode trees. AH provided further specimens and data from the ZSM collection. Geoff Martin 
and John Chainey supported the work carried out at the NHM (London). The work in London was funded by a grant from the SYNTHESYS programme (GB-TAF1048). Patricia Gentili-Poole kindly granted access to photographs of type specimens deposited at the USNM. Wolfgang Nässig allowed to access type material at SFM. Luis E. Parra and Kim Mitter kindly allowed using photographs of $H$. vittata and $H$. mesenata. Maia Vaswani carried out the genitalia dissection work. Support from DFG grants for ecological field work in Ecuador and Costa Rica is acknowledged (BR 2280/1-1, Fi 547/10-1 and 10-2, FOR 816, FOR 402).

\section{References}

Brehm G (2002) Diversity of geometrid moths in a montane rain forest in Ecuador. Dissertation, University of Bayreuth. http://opus.ub.uni-bayreuth.de/volltexte/2003/20

Brehm G, Bodner F, Strutzenberger P, Hünefeld F, Fiedler K (2011) Neotropical Eois (Lepidoptera: Geometridae): checklist, biogeography, diversity, and description patterns. Annals of the Entomological Society of America 104: 1091-1107. doi: 10.1603/AN10050

Brehm G, Strutzenberger P, Fiedler K (2013) Phylogenetic diversity of geometrid moths decreases with elevation in the tropical Andes. Ecography 36: 1247-1253. doi: 10.1111/j.1600-0587.2013.00030.x

Brehm G, Sullivan B (2005) Unusual flight activity of a new species of Hagnagora Druce, 1885 (Lepidoptera: Geometridae) from Costa Rica. Entomologische Zeitschrift 115: 256-260. Druce H (1885a) Descriptions of new species of Lepidoptera Heterocera, chiefly from South America. Proceedings of the Zoological Society of London 1885: 518-536. doi: 10.1111/ j.1469-7998.1885.tb07859.x

Druce H (1885b) Biologica Centrali Americana, Insecta, Lepidoptera-Heterocera, Volume 1, 1881-1900.

Druce H (1893) Biologica Centrali Americana, Insecta, Lepidoptera-Heterocera, Volume 2, 1891-1900.

Janzen DH, Hallwachs W (2014) Dynamic database for an inventory of the macrocaterpillar fauna, and its food plants and parasitoids, of Area de Conservacion Guanacaste (ACG), northwestern Costa Rica, http://janzen.sas.upenn.edu

Janzen DH, and 45 coauthors (2009) Integration of DNA barcoding into an ongoing inventory of complex tropical biodiversity. Molecular Ecology Resources 9 (Suppl. 1): 1-26. doi: $10.1111 / j .1755-0998.2009 .02628 . x$

Forum Herbulot (2014) Statement on accelerated biodiversity assessment (community consensus position). Spixiana 37: 241-242.

Hünefeld F, Brehm G, Pohl H (2013) A simple "hands-off" apparatus to inflate eversible soft parts of the genitalia of small insect specimens. Microscope Research and Technique 76: 258-263. doi: $10.1002 /$ jemt.22161

Lafontaine JD (2004) Noctuoidea, Noctuidae (part), Noctuinae (part - Agrotini). In: Hodges RW (Ed.) The Moths of America North of Mexico fasc. 27.1. The Wedge Entomological Research Foundation, Washington, 385 pp. 
King GE, Parra LE (2011) Contribution to an understanding of the biology and the morphology of the early stages of a Neotropical larentiine: Hagnagora vittata Philippi, 1859 in Chile (Insecta: Lepidoptera: Geometridae). Acta zoologica cracoviensia 54B: 5-15.

Ratnasingham S, Herbert PD (2007) Bold: The barcode of life data system. Molecular Ecology Notes 7: 355-364. doi: 10.1111/j.1471-8286.2007.01678.x

Ratnasingham S, Herbert PD (2013) A DNA-based registry for all animal species: the Barcode Index Number (BIN) system. PLoS ONE 8: e66213. doi: 10.1371/journal.pone.0066213

Sihvonen P, Mutanen M, Kaila L, Brehm G, Hausmann A, Staude HS (2011) Comprehensive molecular sampling yields a robust phylogeny for geometrid moths (Lepidoptera: Geometridae). PLoS ONE 6: e20356. doi: 10.1371/journal.pone.0020356

Strutzenberger P, Brehm G, Fiedler K (2012) DNA barcode sequencing from old type specimens as a tool in taxonomy: a case study in the diverse genus Eois (Lepidoptera: Geometridae). PLoS ONE 7: e49710. doi: 10.1371/journal.pone.0049710

Sullivan JB (2011) Two new species of the Hagnagora anicata clade (Geometridae, Larentiinae) from Costa Rica. ZooKeys 149: 17-29. doi: 10.3897/zookeys.149.2345 